\title{
Evaluation of Simulated Ventilation Techniques With the Upright and Conventional Self-Inflating Neonatal Resuscitators
}

\author{
Indira Narayanan MD, Marvesh Mendhi CRNA MNA, Pooja Bansil MPH, \\ and Patricia S Coffey PhD MPH
}

\begin{abstract}
BACKGROUND: The study assessed the impact of simulated ventilation techniques using upright and conventional self-inflating neonatal resuscitators on delivered tidal volume $\left(V_{T}\right)$ and pressure. METHODS: We analyzed videos of participants ventilating a manikin using an upright (upright, $n=33$ ) and a conventional resuscitator (conventional, $n=32$ ) under normal and low lung compliance. Mask hold, number of fingers squeezing the bag, and degree of bag squeeze were compared with $V_{T}$ and peak inspiratory pressure (PIP). RESULTS: $V_{T}$ and PIP values were higher when using the upright resuscitator than when using the conventional resuscitator. With low compliance, differences in $V_{T}$ were insignificant except with the use of the $\mathrm{OK} / \mathrm{C}$ hold, (upright, $29.6 \pm 4.0 \mathrm{~mL}$, vs conventional, $24.8 \pm 6.0 \mathrm{~mL}, P=.02)$. PIP was significantly higher when using the upright resuscitator with the $\mathrm{OK}$ hold (upright, $36.3 \pm 4.4 \mathrm{~mL}$, vs conventional, $30.3 \pm 6.6 \mathrm{~mL}, P=.009$ ) and when the bag was squeezed by more than half (upright, $33.8 \pm 16.3 \mathrm{~mL}$, vs conventional, $29.3 \pm 9.5 \mathrm{~mL}, P=.046)$. With normal compliance, $V_{T}$ was high with both resuscitators, being significantly higher when using the upright resuscitator with the OK hold (upright, $64.3 \pm 9.5 \mathrm{~mL}$, vs conventional, $45.8 \pm 9.4 \mathrm{~mL} ; P<.001$ ), and when the bag was squeezed using more than 2 fingers (upright, $58.0 \pm 17.2 \mathrm{~mL}$, vs conventional, $45.7 \pm 12.6 \mathrm{~mL}, P=.01$ ) and by more than half (upright, $58.7 \pm 16.6 \mathrm{~mL}$, vs conventional, $45.8 \pm 12.2 \mathrm{~mL}, P=.004$ ). PIP, too, was significantly higher when using the upright resuscitator with the OK hold (upright, $29.3 \pm 3.5 \mathrm{~mL}$, vs conventional, $21.5 \pm 4.0 \mathrm{~mL}, P=<.001$ ) and when the bag was squeezed using more than 2 fingers (upright, $27.2 \pm 7.0 \mathrm{~mL}$, vs conventional, $21.6 \pm 5.7 \mathrm{~mL}, P=.005$ ), and by more than half (upright, $27.6 \pm 6.6 \mathrm{~mL}$, vs conventional, $21.7 \pm 5.4 \mathrm{~mL}, P=.001)$. CONCLUSIONS: Improved mask design, larger bag volume, and upright orientation of the upright resuscitator likely contributed to higher $V_{T}$ and PIP. However, high $V_{T}$ was observed with both resuscitators, possibly due to excessive squeezing of the bag, especially during low compliance. Thus, the design of the resuscitator and manner in which the device is utilized can both significantly influence the $\mathbf{V}_{\mathrm{T}}$ and PIP attained. Key words: resuscitation; newborn; infant; tidal volume; compliance; respiratory care; health care providers; training; capacity building; peak inspiratory pressure. [Respir Care 2017;62(11):1428-1436. (C) 2017 Daedalus Enterprises]
\end{abstract}

\section{Introduction}

Neonatal resuscitation has been carried out for many years, and it has been only in the last decade that evaluations have revealed generation of tidal volumes $\left(\mathrm{V}_{\mathrm{T}}\right)$ that

Dr Narayanan is affiliated with the Department of Pediatrics/Neonatology, Georgetown University Medical Center, Washington, D.C.; Dr Mendhi is affiliated with the College of Nursing, Medical University of South Carolina, Charleston, South Carolina; and Ms Bansil and Dr Coffey are affiliated with the Devices and Tools Program, PATH, Seattle, Washington. are, in some cases, too low or too high, resulting in inadequate ventilation or potential risk for lung injury due to volutrauma. ${ }^{1}$ Such inappropriate ventilation has been documented both with inexperienced users and with some

\footnotetext{
This study is a secondary analysis of the data from a project funded by Laerdal Global Health, a not-for-profit organization, as an independent evaluation of their devices.
}

The study described in this paper was conducted through video analysis. 
experienced staff, such as attending neonatologists. ${ }^{2}$ Therefore, building the capacity of service providers along with equipment innovation assumes considerable importance for improving ventilation techniques.

This paper reports secondary data from an earlier study ${ }^{3}$ (primary) carried out at the Seattle Children's Hospital comparing performance and acceptability of the upright and conventional reusable neonatal self-inflating bag resuscitators with size 1 masks, manufactured by Laerdal Medical, Stavanger, Norway (Fig. 1).

Not only was the vertical orientation of the upright bag different from that of the conventional, but several other features were also different. Earlier reports indicated that besides having fewer inadequate ventilations, the upright was, in general, more acceptable to participants. Due to having fewer parts, it was also found to be easier to disassemble and reassemble for cleaning and sterilization. ${ }^{3,4}$

The devices used in this study did not have PEEP valves. Although the masks of the upright and the conventional are interchangeable, we decided to use the devices in the manner in which they were supplied. Key differences of the upright and conventional are described in Table 1.

The upright (http://www.laerdalglobalhealth.com/doc/ 2516/Upright. Accessed April 14, 2017) may be particularly appropriate for use primarily in low- and middleincome countries, as well as in select situations in highresource countries. T-piece devices, such as the Neopuff included in Bennett et al, ${ }^{5}$ were not included in this study because they require a continuous flow of blended air and oxygen that is not available in many centers in low- and middle-income countries (these settings were the focus of the primary study). The objective of the present study was to assess the impact of the techniques of simulated ventilation applied on a manikin with the 2 designs of resuscitators on mean $\mathrm{V}_{\mathrm{T}}$ and peak inspiratory pressures (PIP).

\section{Hypothesis}

$\mathrm{V}_{\mathrm{T}}$ and PIP delivered with resuscitators are not only influenced by the device design but also by the ventilation techniques employed by operators, including their perception of changes in lung compliance and their ability to make necessary adjustments.

Dr Narayanan presented a version of this paper at the Pediatric Academic Society meeting, held April 30 to May 3, 2016, in Baltimore, Maryland.

The authors have disclosed no conflicts of interest.

Correspondence: Patricia S Coffey PhD MPH, Devices and Tools Program, PATH, PO Box 900922, Seattle, WA 98121. E-mail: pcoffey@path.org.

DOI: $10.4187 /$ respcare 05328

\section{QUICK LOOK}

\section{Current knowledge}

Evaluations of ventilation during neonatal resuscitation have revealed, on occasions, delivery of tidal volumes $\left(\mathrm{V}_{\mathrm{T}}\right)$ that are either too low or too high, resulting in inadequate ventilation or potential risk for lung injury due to volutrauma both with inexperienced users as well as with some experienced staff, such as neonatologists.

\section{What this paper contributes to our knowledge}

High $\mathrm{V}_{\mathrm{T}}$ was observed with both types of self-inflating reusable resuscitators (upright and conventional), but more so when using the upright with normal compliance. The larger bag size and excessive squeezing, along with better mask fixation, may have resulted in higher $\mathrm{V}_{\mathrm{T}}$ in the upright resuscitator. This study highlights a lack of recognition of changes in compliance. Capacity building needs to address proper mask fixation to improve mask seal, avoidance of excessive bag squeezing, and looking into better recognition of changes in compliance. Not only the design of the resuscitator influences the $\mathrm{V}_{\mathrm{T}}$ and pressures delivered, but also the manner in which the device is handled.

\section{Methods}

The primary study was approved by the Seattle Children's Hospital Institutional Review Board (approval 14096) and the PATH Research Ethics Committee (HS692). Two groups participated in the primary study: (1) experienced users, including neonatologists, NICU nurses, and respiratory therapists who had used a conventional bag and mask to resuscitate babies in the past; and (2) participants designated as inexperienced users, including mid-

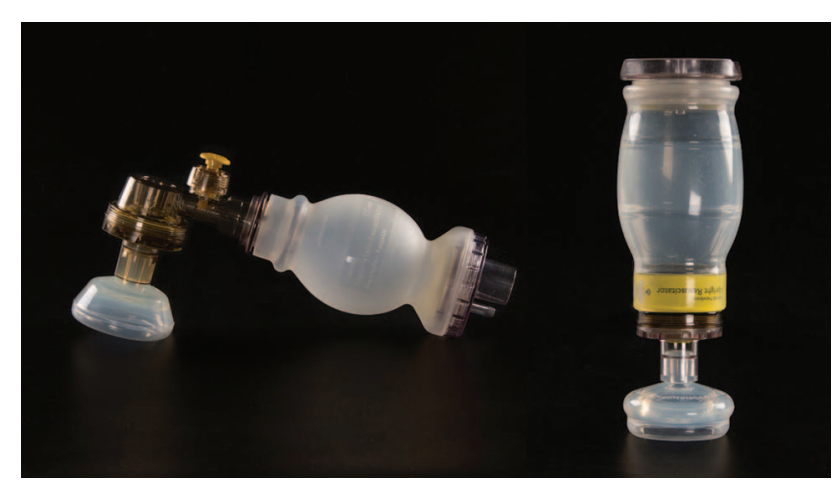

Fig. 1. The conventional resuscitator (left) and upright resuscitator (right). 


\section{Ventilation Techniques With Neonatal Resuscitators}

Table 1. Differences in the Conventional and Upright Self-Inflating, Reusable Neonatal Resuscitators

\begin{tabular}{|c|c|}
\hline Conventional Neonatal Resuscitator & Upright Neonatal Resuscitator \\
\hline $\begin{array}{l}\text { 1. Bag is horizontal, at right angles to the mask stem, and with } \\
\text { a bag volume of } 220 \mathrm{~mL} \text {. }\end{array}$ & $\begin{array}{l}\text { Bag is vertical, in line with the mask stem, bag wall is thicker, and volume } \\
\text { is } 320 \mathrm{~mL} \text { (slightly larger). The bag can be compressed to reduce the } \\
\text { size where required for easy transportation. }\end{array}$ \\
\hline $\begin{array}{l}\text { 2. Upper portion of the mask has a smaller diameter and is } \\
\text { softer. The mask stem is smooth, slipping easily into the bag } \\
\text { stem, but does not permit firm fixation. }\end{array}$ & $\begin{array}{l}\text { The mask has a wider top portion with a firmer rim and a softer lower } \\
\text { portion. The mask stem has a small ridge that can slot into a groove on } \\
\text { the inner side of the bag stem, permitting a firm fit. These features } \\
\text { permit a better mask hold and a more exact placement on the baby's } \\
\text { face, potentially helping to reduce mask leak. }\end{array}$ \\
\hline $\begin{array}{l}\text { 3. The pressure relief (pop-off) valve is close to and above the } \\
\text { mask stem (pressure limit is } 35 \mathrm{~cm} \mathrm{H}_{2} \mathrm{O} \text { ). }\end{array}$ & $\begin{array}{l}\text { The pressure relief (pop-off) valve is located at the top of the bag (pressure } \\
\text { limit is higher, } 45 \mathrm{~cm} \mathrm{H}_{2} \mathrm{O} \text { ). }\end{array}$ \\
\hline 4. The conventional has 9 major parts in addition to the mask. & $\begin{array}{l}\text { The upright has } 6 \text { major parts in addition to the mask. This permits easier } \\
\text { disassembly and reassembly during reprocessing of these reusable } \\
\text { devices.* }\end{array}$ \\
\hline $\begin{array}{l}\text { From Reference 3. } \\
\text { http://www.laerdalglobalhealth.com/doc/2516/Upright. Accessed November 30, } 2016 . \\
\text { * http://www.path.org/publications/detail.php?i=2601. Accessed November 30, } 2016 .\end{array}$ & \\
\hline
\end{tabular}

wifery and respiratory therapy students who had received competency-based training but had never actually resuscitated an infant. These 2 groups were identified to determine the influence that experience had on ventilation techniques.

After obtaining informed consent and demographic information, the length and width of the dominant hand of each participant were recorded using a centimeter grid. Hand-size cutoff points were determined using hand anthropometry data (http://usability.gtri.gatech.edu/ eou_info/hand_anthro.php. Accessed November 30, 2016) collected by the Georgia Tech Research Institute (Atlanta, Georgia). Hand-size categories were used as a stratification variable for study end points.

Participants were given a brief orientation using a standardized video demonstrating the 2-point mask hold, based on the report of Wood et $\mathrm{al}^{6}$ where it was described as the optimal hold. They then evaluated the 2 devices in randomized order using a commercially available test lung (ASL 5000, IngMar Medical, Pittsburgh, Pennsylvania) connected to the training manikin (NeoNatalie, Laerdal Global Health, Stavanger, Norway) with an integrated chest-rise module.

As noted in the primary study, participants ventilated the manikin including an epoch of low compliance $\left(0.5 \mathrm{~mL} / \mathrm{cm} \mathrm{H}_{2} \mathrm{O}\right)$ with a resistance of $160 \mathrm{~cm} \mathrm{H}_{2} \mathrm{O} / \mathrm{L} / \mathrm{s}$ for $1 \mathrm{~min}$, and an epoch of normal compliance $(2.0 \mathrm{~mL} / \mathrm{cm}$ $\mathrm{H}_{2} \mathrm{O}$ ) with resistance of $50 \mathrm{~cm} \mathrm{H}_{2} \mathrm{O} / \mathrm{L} / \mathrm{s}$ for $2 \mathrm{~min}$. They were told that the compliance would change during the evaluation, but they were not informed of the exact time when the change was instituted. Changes in compliance were introduced to mimic the natural sequence of events during birth asphyxia, and in preterm babies with initial low compliance followed by normalization to determine whether participants could detect these changes and make necessary adjustments in the ventilation techniques. The $\mathrm{V}_{\mathrm{T}}$ and PIP generated by each cycle were recorded. Adequate ventilation was defined as a $\mathrm{V}_{\mathrm{T}}$ of $5 \mathrm{~mL} / \mathrm{kg}$ and excessive ventilation as greater than $15 \mathrm{~mL} / \mathrm{kg}$, equivalent to 15 and $45 \mathrm{~mL}$, respectively, for a $3-\mathrm{kg}$ baby. ${ }^{7}$

\section{Evaluation of Ventilation Techniques}

We recorded videos of and photographed hands, resuscitator devices, and the manikin during simulated ventilation for all consenting participants. A camera was fixed on a stand near the study site, and the orientation was changed appropriately for right-handed and left-handed participants. After initial viewing, criteria for classification of each aspect of ventilation were developed and pretested. The videos were evaluated for (a) the type of mask hold, (b) the number of fingers used to squeeze the bag, and (c) the degree to which the bag was squeezed. These variables were observed separately related to low and normal compliance epochs. Although the number of fingers used varied, the variable was dichotomized into 2 fingers and more than $2(2+)$ fingers. Bag squeeze was evaluated subjectively and categorized into 2 groups: up to half, and more than half. Two of the authors independently evaluated videos and photographs and compared results. In case of disagreement, the videos were viewed again together and consensus was reached.

Mean $\mathrm{V}_{\mathrm{T}}$ and PIP were evaluated for the type of mask hold, the number of fingers used to squeeze the bag, and the degree to which the bag was squeezed. Values of $V_{T}$ and PIP were recorded by the test lung simulator. One-way analysis of variance was used to compare means within and across devices. $P<.05$ were considered statistically significant. All statistical analyses were conducted in Stata 13.1 (Statacorp, College Station, Texas). 
Table 2. Tidal Volumes by Type of Mask Hold, Number of Fingers Used to Squeeze the Bag, and Degree to Which the Bag Was Squeezed

\begin{tabular}{|c|c|c|c|c|c|}
\hline & \multicolumn{2}{|c|}{ Conventional Resuscitator } & \multicolumn{2}{|c|}{ Upright Resuscitator } & \multirow[b]{2}{*}{$P^{*}$} \\
\hline & $n$ & Mean $\pm \mathrm{SD}(\mathrm{mL})$ & $n$ & Mean $\pm \mathrm{SD}(\mathrm{mL})$ & \\
\hline \multicolumn{6}{|c|}{ Low compliance $\left(0.5 \mathrm{~mL} / \mathrm{cm} \mathrm{H}_{2} \mathrm{O}\right)$} \\
\hline \multicolumn{6}{|l|}{ Mask hold type $\dagger$} \\
\hline 2-point hold & 10 & $23.1 \pm 7.1$ & 15 & $28.0 \pm 7.3$ & .12 \\
\hline OK hold & 14 & $24.8 \pm 6.0$ & 14 & $29.6 \pm 4.0$ & .02 \\
\hline \multicolumn{6}{|c|}{ Number of fingers used to squeeze the bag } \\
\hline 2 fingers & 9 & $22.2 \pm 6.0$ & 5 & $25.1 \pm 3.3$ & .35 \\
\hline $2+$ fingers & 22 & $26.0 \pm 8.0$ & 27 & $28.1 \pm 7.5$ & .36 \\
\hline \multicolumn{6}{|c|}{ Degree of bag squeeze } \\
\hline Less than half & 6 & $23.2 \pm 4.3$ & 4 & $23.6 \pm 2.8$ & .88 \\
\hline More than half & 25 & $25.3 \pm 8.2$ & 28 & $28.2 \pm 7.3$ & .19 \\
\hline \multicolumn{6}{|c|}{ Normal compliance $\left(2.0 \mathrm{~mL} / \mathrm{cm} \mathrm{H}_{2} \mathrm{O}\right)$} \\
\hline \multicolumn{6}{|l|}{ Mask hold type } \\
\hline 2-point hold & 12 & $40.9 \pm 14.2$ & 14 & $50.5 \pm 19.0$ & .16 \\
\hline OK hold & 13 & $45.8 \pm 9.4$ & 13 & $64.3 \pm 9.5$ & $<.001$ \\
\hline \multicolumn{6}{|c|}{ Number of fingers used to squeeze the bag } \\
\hline 2 fingers & 10 & $38.7 \pm 13.6$ & 6 & $51.8 \pm 12.7$ & .08 \\
\hline $2+$ fingers & 21 & $45.7 \pm 12.6$ & 26 & $58.0 \pm 17.2$ & .01 \\
\hline \multicolumn{6}{|c|}{ Degree of bag squeeze } \\
\hline Up to half & 8 & $37.0 \pm 14.3$ & 6 & $48.7 \pm 14.5$ & .15 \\
\hline More than half & 23 & $45.8 \pm 12.2$ & 26 & $58.7 \pm 16.6$ & .004 \\
\hline
\end{tabular}

\section{Results}

A total of 65 videos were analyzed with 32 participants using the conventional and 33 participants using the upright, which included 24 experienced and 9 inexperienced users. All 65 videos were evaluated, but certain features could not be visualized properly in a few videos. Thus, we analyzed varying numbers of video sequences for each aspect of the ventilation process, including type of mask hold, the number of fingers used to squeeze the bag, and the degree to which the bag was squeezed, as noted in Tables 2 and 3. Hand size was average or below average in 19 participants, and above average in 14 participants.

The 2 evaluators agreed on most issues in the evaluation of the videos and photographs. There were differences only in two instances. In one case, an evaluator classified mask hold as a 2-point hold and the second person as an OK hold; on review, consensus was reached on the OK hold. In the other instance, on review of the number of fingers used to squeeze the bag, consensus was reached with $2+$ fingers.

\section{Ventilation Techniques}

Rolling the mask over the face could be clearly seen in 30 out of the 32 videos with the conventional. Among these, 15 participants rolled on the mask, whereas 15 did not. With the upright, 31 videos could be evaluated properly, in which the roll-on maneuver was carried out in 16 cases. Jaw lift to maintain appropriate position of the airway could be properly evaluated in 31 cases using the conventional and among these, jaw lift was applied in 26 and not done properly in 5 . With the upright, all 33 videos could be evaluated. Twenty-eight participants applied the jaw lift while 5 did not carry out this step appropriately.

\section{Types of Mask Holds Observed}

Three major types of mask holds were observed: 2-point top hold, OK rim hold, and modified OK rim hold with distortion (Fig. 2). The 2-point top hold (also referred to as the 2-point hold) occurred when the thumb and index finger applied balanced pressure to the top, flat portion of the mask where the silicone was thickest, with the main pressure being applied through the tips of the thumb and index finger. The stem was not held and the fingers did not encroach onto the skirt of the mask. This hold was noted in 10 cases using the conventional and 15 using the upright. The $\mathrm{OK}$ rim hold (also referred to as a $\mathrm{C}$ hold or $\mathrm{OK}$ hold) occurred when the thumb and index finger formed a $\mathrm{C}$-shape and were placed around the top portion of the mask and applied an even distribution of pressure to the 
Table 3. Peak Inspiratory Pressure by Type of Mask Hold, Number of Fingers Used to Squeeze the Bag, and Degree to Which the Bag Was Squeezed

\begin{tabular}{|c|c|c|c|c|c|}
\hline & \multicolumn{2}{|c|}{ Conventional Resuscitator } & \multicolumn{2}{|c|}{ Upright Resuscitator } & \multirow[b]{2}{*}{$P^{*}$} \\
\hline & $n$ & Mean $\pm \mathrm{SD}\left(\mathrm{cm} \mathrm{H}_{2} \mathrm{O}\right)$ & $n$ & Mean $\pm \mathrm{SD}\left(\mathrm{cm} \mathrm{H}_{2} \mathrm{O}\right)$ & \\
\hline \multicolumn{6}{|l|}{ Low compliance $\left(0.5 \mathrm{~mL} / \mathrm{cm} \mathrm{H}_{2} \mathrm{O}\right)$} \\
\hline \multicolumn{6}{|l|}{ Mask hold type $\dagger$} \\
\hline 2-point hold & 10 & $27.0 \pm 11.0$ & 15 & $32.1 \pm 5.2$ & .13 \\
\hline OK hold & 14 & $30.3 \pm 6.6$ & 14 & $36.3 \pm 4.4$ & .009 \\
\hline \multicolumn{6}{|c|}{ Number of fingers used to squeeze the bag } \\
\hline 2 fingers & 9 & $26.3 \pm 9.6$ & 5 & $31.1 \pm 4.4$ & .32 \\
\hline $2+$ fingers & 22 & $30.3 \pm 8.5$ & 27 & $35.6 \pm 6.5$ & .13 \\
\hline \multicolumn{6}{|l|}{ Degree of bag squeeze } \\
\hline Less than half & 6 & $28.4 \pm 5.9$ & 4 & $28.9 \pm 4.1$ & .89 \\
\hline More than half & 25 & $29.3 \pm 9.5$ & 28 & $33.8 \pm 16.3$ & .046 \\
\hline \multicolumn{6}{|l|}{ Normal compliance $\left(2.0 \mathrm{~mL} / \mathrm{cm} \mathrm{H}_{2} \mathrm{O}\right)$} \\
\hline \multicolumn{6}{|l|}{ Mask hold type } \\
\hline 2-point hold & 12 & $18.8 \pm 6.4$ & 14 & $24.6 \pm 8.4$ & .06 \\
\hline OK hold & 13 & $21.5 \pm 4.0$ & 3 & $29.3 \pm 3.5$ & $<.001$ \\
\hline \multicolumn{6}{|c|}{ Number of fingers used to squeeze the bag } \\
\hline 2 fingers & 10 & $18.2 \pm 6.0$ & 6 & $23.9 \pm 5.6$ & .08 \\
\hline $2+$ fingers & 21 & $21.6 \pm 5.7$ & 26 & $27.2 \pm 7.0$ & .005 \\
\hline \multicolumn{6}{|l|}{ Degree of bag squeeze } \\
\hline Up to half & 8 & $17.2 \pm 6.4$ & 6 & $22.2 \pm 6.2$ & .17 \\
\hline More than half but not near full & 23 & $21.7 \pm 5.4$ & 26 & $27.6 \pm 6.6$ & .001 \\
\hline
\end{tabular}

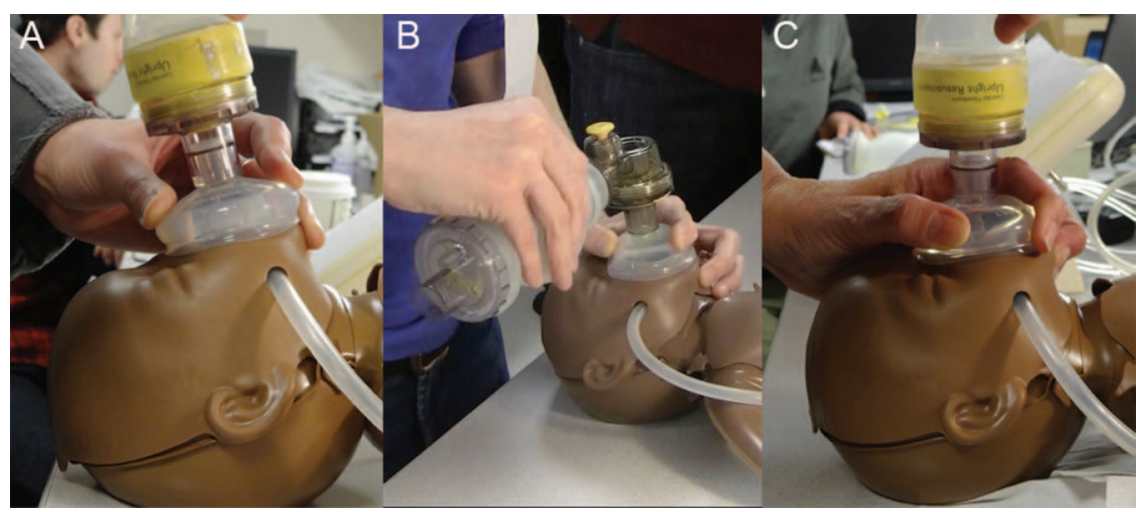

Fig. 2. Common mask holds seen in this study. A: 2-point hold, B: OK hold, and C: OK hold with distortion.

outer edge. Thus, a wider area of the mask was in contact with the thumb and index finger. The OK hold was used by 14 participants each using the conventional and upright devices. The modified OK rim hold with distortion was similar to the OK hold and occurred when the finger encircling the upper rim not only extended to the lower rim, but also caused mask distortion. Since we felt mask distortion was more likely to be associated with increased mask leak, we classified it separately. The OK hold with distortion was seen only with the mask of the conventional device $(n=3)$. Other holds were observed rarely. In 3 cases, only 1 digit, the finger or the thumb, touched the stem, and the other digit was placed on top of the mask close to the stem. We did not observe the typical type of stem hold described by Woods et $\mathrm{al}^{6}$ where both the thumb and index finger actually held the stem. One participant had the thumb on the forehead with the tips of the index and middle fingers on the top rim of the mask. There was no attempt to apply the jaw lift, and the excessive downward pressure tended to squash down the manikin's head on the table. Participants who made very frequent changes in the manner in which the mask was held were also placed 


\section{Ventilation Techniques With Neonatal Resuscitators}

in this category. These holds were observed with 4 participants using the conventional, and 3 participants using the upright. $\mathrm{V}_{\mathrm{T}}$ and PIP assessed for the 2 most common mask holds, 2-point hold and the OK hold, are noted in Tables 2 and 3.

\section{$\mathbf{V}_{T}$ Related to Mask Holds, Number of Fingers Used, and Degree of Bag Squeeze}

$\mathrm{V}_{\mathrm{T}}$ are displayed in Table 2. The $P$ values noted indicate $t$ test $P$ values comparing the $\mathrm{V}_{\mathrm{T}}$ means across the 2 devices. With low compliance, $\mathrm{V}_{\mathrm{T}}$ was higher with the upright than with the conventional related to mask hold, number of fingers used, and bag squeeze, but these differences were significant only relative to the OK hold $(P=.02)$. In addition, with low compliance, 25 of 31 participants $(80.6 \%)$ using the conventional, and 28 of 32 participants (87.5\%) using the upright squeezed the bag by more than half. With normal compliance, $\mathrm{V}_{\mathrm{T}}$ was high with both devices, but significantly higher when using the upright device as compared with using the conventional device when the OK hold was used $(P<.001)$, more than 2 fingers were used to squeeze the bag $(P=.01)$, and when the bag was squeezed by more than half $(P=.004)$. More than half of the participants used more than 2 fingers, and also squeezed the bag excessively with both resuscitators. A number of participants continued to squeeze the bag by more than half even when the compliance became normal ( 23 of 31 , or $74.1 \%$, when using the conventional, and 26 of 32 , or $81.3 \%$, when using the upright).

Analysis of variance $P$ values comparing mean values for $\mathrm{V}_{\mathrm{T}}$ across types of mask hold, the numbers of fingers used, and the degree of bag squeeze separately for the conventional resuscitator and for the upright resuscitator, not shown in Table 2, were also calculated. They were not significant, except for $\mathrm{V}_{\mathrm{T}}$ for the upright resuscitator with normal compliance when the OK/C hold was compared with the 2-point hold. $\mathrm{V}_{\mathrm{T}}$ was higher with $\mathrm{OK} / \mathrm{C}$ hold $(64.3 \pm 9.5 \mathrm{~mL})$ than with the 2-point hold $(50.5 \pm 19.0$ $\mathrm{mL}), P=.027$.

\section{PIP Related to Mask Holds, Number of Fingers Used, and Degree of Bag Squeeze}

PIP values are shown in Table 3. PIP was higher using the upright than using the conventional. For low compliance, PIP was significantly higher using the OK hold $(P=.009)$ and when the bag was squeezed by more than half $(P=.046)$. With normal compliance, PIP was significantly higher using the upright with the OK hold $(P<$ $.001)$, with the use of more than 2 fingers $(P=.005)$, and with the bag being squeezed by more than half $(P=.001)$.

Analysis of variance $P$ values comparing means for PIP across type of mask hold, the numbers of fingers used, and
Table 4. The Relation of the Degree of Bag Squeeze by Mask Hold

\begin{tabular}{|c|c|c|c|}
\hline & 2-Point Hold & OK Hold & \\
\hline & $n(\%)$ & $n(\%)$ & $P^{*}$ \\
\hline \multicolumn{4}{|c|}{ Low compliance $\left(0.5 \mathrm{~mL} / \mathrm{cm} \mathrm{H}_{2} \mathrm{O}\right)$} \\
\hline \multicolumn{4}{|c|}{ Conventional resuscitator } \\
\hline Up to half & $3(30.0)$ & $2(14.3)$ & .69 \\
\hline More than half & $7(70.0)$ & $12(85.7)$ & .41 \\
\hline$P$ value $\dagger$ & .24 & .03 & \\
\hline \multicolumn{4}{|l|}{ Upright resuscitator } \\
\hline Up to half & $4(26.7)$ & $0(0)$ & - \\
\hline More than half & $11(73.3)$ & $14(100)$ & .039 \\
\hline$P$ value $\dagger$ & .10 & - & \\
\hline \multicolumn{4}{|c|}{ Normal compliance $\left(2.0 \mathrm{~mL} / \mathrm{cm} \mathrm{H}_{2} \mathrm{O}\right)$} \\
\hline \multicolumn{4}{|c|}{ Conventional resuscitator } \\
\hline Up to half & $2(16.7)$ & $5(38.5)$ & .58 \\
\hline More than half & $10(83.3)$ & $8(61.5)$ & .30 \\
\hline$P$ value $\dagger$ & .054 & .42 & \\
\hline \multicolumn{4}{|l|}{ Upright resuscitator } \\
\hline Up to half & $3(20.0)$ & $1(7.7)$ & - \\
\hline More than half & $12(80.0)$ & $12(92.3)$ & .38 \\
\hline$P$ value $\dagger$ & .046 & - & \\
\hline \multicolumn{4}{|c|}{$\begin{array}{l}\text { * Test of equal proportions comparing the proportions between types of mask hold. } \\
\dagger \text { Test of equal proportions comparing the proportions between degrees of bag squeeze. } \\
- \text { indicates too few numbers to determine significance. }\end{array}$} \\
\hline
\end{tabular}

the bag squeeze for the conventional and for the upright, not shown in the table, were also calculated. They were not significant, except for PIP across type of mask hold for the upright with low compliance. PIP was significantly higher with the OK/C hold $(36.3 \pm 4.4 \mathrm{~mL})$ than with the 2 point hold $(32.1 \pm 5.2 \mathrm{~mL}), P=.026$.

Interestingly, participants in general did not try to override the pressure-relief valve, even when they could not visualize chest rise. As shown in Table 3, in no case did the PIP exceed the set pressure limit for the pressure-relief valve of $35 \mathrm{~cm} \mathrm{H}_{2} \mathrm{O}$ in the conventional and $45 \mathrm{~cm} \mathrm{H}_{2} \mathrm{O}$ in the upright.

In view of the fact that we did not have data on leak, we reviewed "surrogate" data that could possibly provide information on whether better mask seal could have had some correlation with the higher $\mathrm{V}_{\mathrm{T}}$ in this study. Bag size was not likely to have been an influencing factor because it was seen with both of the bags. Hence, we compared the degree of bag squeeze applied by the participants with the 2 most common mask holds, the 2-point and OK holds (Table 4). In comparing the relation of the bag squeeze between the 2-point and OK holds, the only significant difference was the proportion that squeezed by more than half with the upright bag with low compliance $(P=.039)$. However, there were no statistically significant differences in the degree of bag squeeze (both up to half and more than half) between the 2-point and OK holds when using 


\section{Ventilation Techniques With Neonatal Resuscitators}

the conventional with low and normal compliance and when using the upright with normal compliance.

\section{Relation to Hand Size and Experience}

For both resuscitators at low and normal compliance, we compared proportions of the 3 elements of ventilation technique - mask hold type, the number of fingers used to squeeze, and the degree of bag squeeze - by user group (experienced and inexperienced users) and hand size (below-average and average hand size, and above-average hand size), and found no significant differences (data not shown).

\section{Discussion}

Evaluation of videos of ventilation techniques has provided some interesting insights that might have implications for capacity building and supervision/mentoring of service providers relevant to resuscitation. In initiating ventilation, the proper positioning of the head and neck to promote a patent airway is important. In this study, most of the participants did apply this step. Most did roll the mask onto the face from the chin, a step that helps to apply the mask in a better manner and is promoted by some manuals.

Related to the mask holds, the 2 most common types of mask hold observed were the $\mathrm{OK}$ or $\mathrm{C}$, and the 2-point holds. The OK hold tends to apply pressure over a larger area of the mask, probably helping to promote a better mask seal. It was slightly more common when using the conventional device where the top flat portion of the mask is smaller and the upper rim of the mask is softer. It is possible that the OK hold may have made the user more confident in developing a good seal. With this hold, however, it was also noted that with the smaller top portion and the less-firm upper rim of the mask in the conventional, in a few cases, the finger slipped down and pressed on the lower rim, tending to buckle or lift up a small part leading to distortion that potentially could affect mask seal. This was not observed when using the upright where the larger, upper, flat portion and the firmer upper rim of the mask helped position the fingers in a more appropriate manner. In addition, the softer lower rim likely permitted a better fixation on the face. The 2 features together were more conducive to improving mask seal. The vertical orientation of the upright may have also promoted and helped maintain better fixation of the mask. In contrast, the horizontal orientation of the conventional device may have a potential counteractive influence on maintaining the mask seal, more so with prolonged ventilation, especially if the hand actively squeezing the bag tends to sag. This is consistent with earlier results that indicated that participants found it easier to hold and fix the mask of the upright bag. ${ }^{3}$ Thallinger et $\mathrm{al}^{4}$ have further documented that the mask leak was significantly less when using the upright as compared with using the conventional. In the present study, too, the relation of the degree of bag squeeze by the mask holds (Table 4) provided indirect support to decreased mask leak when using the upright device.

Self-inflating bags with volumes of $220-240 \mathrm{~mL}$ are more than enough to provide adequate ventilation for the newborn, as the required $\mathrm{V}_{\mathrm{T}}$ for a term, normal-weight baby is only $6-8 \mathrm{~mL} / \mathrm{kg} .{ }^{7}$ Nonetheless, some have recommended that a bag size of at least $500 \mathrm{~mL}$ is required for neonatal ventilation 8 in that the larger bag size can compensate for mask leak. Interestingly, this size is still recommended for term newborn babies, particularly in delivery rooms in some low-resource countries. ${ }^{9}$ In these instances, the intermediate $320 \mathrm{~mL}$ size of the upright bag has the advantage of being in between 220 and $500 \mathrm{~mL}$. As shown in this study, although excessive $\mathrm{V}_{\mathrm{T}}$ can occur with all bag sizes, larger bags carry a greater risk of delivering high, potentially harmful levels that carry even greater risks in preterm babies, especially when the bag is squeezed excessively in the presence of better mask seal and less leak. In addition, the feedback on chest rise provided by the manikin connected to the test lung and chest rise module may not be the same as with the manikin alone, contributing to increased bag squeezing by participants. This may be even more variable in real-life situations during ventilation of babies.

Ventilation risks include inadequate ventilation as well as excessively high $\mathrm{V}_{\mathrm{T}}$. In recent years, volume-targeted ventilation has been considered more suitable than pressure-limited ventilation, especially in preterm infants. ${ }^{7} \mathrm{~V}_{\mathrm{T}}$ is affected to a significant extent by the manner in which the mask is applied and fixed, which influences mask seal. It is also governed by the size of the bag and the manner in which it is squeezed. Thus, the final $\mathrm{V}_{\mathrm{T}}$ delivered depends on a careful balance between all these elements. The degree of bag squeeze also needs to be determined by the bag size and the existing lung compliance. Although these elements may present challenges, it is important to try and incorporate them into training programs in order to attain optimal $\mathrm{V}_{\mathrm{T}}$.

In this study, the number of fingers used to squeeze the bag was variable, although a larger number of participants tended to use more than 2 fingers. Overall, however, the number of fingers used seemed to play a less important role than the degree to which the bag was squeezed. This may have some importance for individuals who have difficulty in administering adequate ventilation using 2 fingers. Our results suggest that it would be better to focus more attention on the manner in which the bag is squeezed, in general, avoiding squeezing by more than half.

Although there have been some challenges related to assessing chest rise, ${ }^{10}$ it is probably better not to aim for a 
good chest rise but rather for one that mimics the quiet breathing of a normal newborn - of course correlated with other parameters including heart rate and improvement in the condition of the baby. Whereas the priority in lowresource centers are the normal-term, more mature preterm, and larger low-birthweight babies, the challenge becomes even greater in advanced centers dealing with more preterm babies where the margin of safety becomes narrower and potential dangers greater.

Currently, technology is available that can be used during training or mentoring sessions to monitor $\mathrm{V}_{\mathrm{T}}$, although it may not be practical for routine use in low-resource centers. ${ }^{11,12}$ The pressure-relief valve helps release excessive pressure during ventilation that may have accounted for the rise in PIP being proportionately less than the increase in $\mathrm{V}_{\mathrm{T}}$ even when the bag was squeezed excessively. Ultimately, exploring for a suitable mechanism to avoid delivery of needlessly high $\mathrm{V}_{\mathrm{T}}$ with an override option for special situations such as low compliance, while challenging, may be a useful addition to the armamentarium for providing more safe and effective ventilation, especially with preterm babies.

Boldingh et $\mathrm{al}^{13}$ reported that around 1 in 4 physicians failed to recognize correct compliance levels when using a self-inflating bag and showed limited improvement even after an educational intervention. They observed more sub-optimal ventilation in low compliance settings. ${ }^{13}$ In our study, we observed that a number of participants tended to squeeze the bag rather excessively during the period of the initial low compliance. Interestingly, they not only continued to do so even after the compliance improved, but actually squeezed the bag to an even greater extent during normal compliance. They were, apparently, not able to determine when the compliance improved and the "resistance" to ventilation decreased. Hence, instead of now decreasing the degree of squeezing, they continued to squeeze strongly with, in some, the squeeze increasing to an even greater extent. The absence or the inadequacy of the adjustments made in ventilation when the compliance decreased accounted for the even higher $\mathrm{V}_{\mathrm{T}}$ and PIP noted when the compliance was normal. It is possible that the high values noted, particularly with normal compliance, may have been less had the normal compliance been introduced before the low-compliance sequence along with a break between simulation sessions, as was done by Thallinger et al. ${ }^{4}$ However, initiating ventilation with low compliance, followed by normal compliance without intimation of the exact timing of the change, more closely mimicked reality in clinical practice.

A number of the training manuals on neonatal resuscitation in advanced centers (such as the Neonatal Resuscitation Program) do address many of these issues. ${ }^{14}$ Manuals on basic resuscitation such as the training manual for Helping Babies Breathe (https://www.aap.org/en-us/ advocacy-and-policy/aap-health-initiatives/helpingbabies-survive/Pages/Helping-Babies-Breathe.aspx. Accessed November 30, 2016) may not necessarily deal with such details in order to keep the training at a more basic level. Interestingly, the Indian national manual on basic resuscitation (Navjaat Shishu Suraksha Karyakram) does target a few issues, such as the placement of the mask by promoting a hold similar to the OK hold with "thumb, index, and/or middle finger encircling the rim of the mask in shape of letter ' $\mathrm{C}$,' "' and cautioning that the bag squeeze should be sufficient only to produce a gentle chest rise as in normal breathing (http://www.nihfw.org/pdf/NCHRCPublications/NavjaatShishuTrgMan.pdf. Accessed November 30, 2016). In this study, we did note that some participants tended to let their fingers extend below the edge of the upper rim of the mask, which can promote distortion and mask leak. They also tended to squeeze harder. Hence, optimal modalities of ventilation may need to be stressed during training. Ultimately, a balance has to be maintained between keeping basic resuscitation guidelines as simple as possible and highlighting steps that can support better mask seal, avoid distortion and leak, and promote just enough squeezing of the bag to produce a chest rise similar to gentle, normal breathing. These issues also need to be reviewed in follow-up supportive supervision and mentoring to promote quality of care, and have relevance wherever the self-inflating bag is used globally. This study is limited by the subjective nature of the video review as well as lack of mask leak data.

\section{Conclusions}

High $\mathrm{V}_{\mathrm{T}}$ were observed with both resuscitators, but more so when using the upright with normal compliance. The larger bag size and excessive squeezing, especially during normal compliance, may have resulted in higher $\mathrm{V}_{\mathrm{T}}$. The upright orientation and improved mask design, too, may have contributed to better mask fixation, which in turn could have further increased $\mathrm{V}_{\mathrm{T}}$. This study also highlights a lack of recognition of changes in compliance during ventilation. Capacity building thus needs to address not only proper mask fixation to improve mask seal, but also avoidance of excessive bag squeezing, and looking into more innovative methods of better recognition of changes in compliance. This study has revealed that it is not only the design of the resuscitator that influences the $\mathrm{V}_{\mathrm{T}}$ and PIP attained, but also the manner in which the device is handled.

\section{ACKNOWLEDGMENTS}

We thank Dr Jayashree Ramasethu and Dr M Kabir Abubakar, Division of Neonatal Perinatal Medicine, MedStar Georgetown University Hospital, for assistance with reviewing the manuscript. We also thank Robert M DiBlasi, Respiratory Therapy, Seattle Children's, and Eugene A Saxon, Devices and Tools Program, PATH, for their technical insight. We es- 


\section{Ventilation Techniques With Neonatal Resuscitators}

pecially thank Abra Greene for her superb assistance with manuscript production.

\section{REFERENCES}

1. Hillman NH, Moss TJM, Kallapur SG, Bachurski C, Pillow JJ, Polglase GR, et al. Brief, large tidal volume ventilation initiates lung injury and a systemic response in fetal sheep. Am J Respir Crit Care Med 2007;176(6):575-581.

2. O'Donnell CP, Davis PG, Lau R, Dargaville PA, Doyle LW, Morley CJ. Neonatal resuscitation 2: an evaluation of manual ventilation devices and face masks. Arch Dis Child Fetal Neonatal Ed 2005; 90(5):F392-F396.

3. Coffey PS, Saxon EA, Narayanan I, DiBlasi RM. Performance and acceptability of two self-inflating bag-mask neonatal resuscitator designs. Respir Care 2015;60(9):1227-1237.

4. Thallinger M, Ersdal HL, Ombay C, Eilevstjønn J, Størdal K. Randomized comparison of two neonatal resuscitation bags in manikin ventilation. Arch Dis Child Fetal Neonatal Ed 2016;101(4):F299F303.

5. Bennett S, Finer NN, Rich W, Vaucher Y. A comparison of three neonatal resuscitation devices. Resuscitation 2005;67(1):113-118.

6. Wood FE, Morley CJ, Dawson JA, Kamlin COF, Owen LS, Donath $\mathrm{S}$, Davis PG. Improved techniques reduce face mask leak during simulated neonatal resuscitation: study 2. Arch Dis Child Fetal Neonatal Ed 2008;93(3):F230-F234.
7. Kattwinkel J, Stewart C, Walsh B, Gurka M, Paget-Brown A. Responding to compliance changes in a lung model during manual ventilation: Perhaps volume, rather than pressure, should be displayed. Pediatr 2009;123(3):e465-e470.

8. Field D, Milner AD, Hopkin IE. Efficiency of manual resuscitators at birth. Arch Dis Child 1986;61(3):300-302.

9. United Nations Children's Fund (UNICEF). Toolkit for setting up special care newborn units, stabilization units and newborn care corners. New Delhi: UNICEF; 2008.

10. Brugada M, Schilleman K, Witlox RS, Walther FJ, Vento M, Te Pas $\mathrm{AB}$. Variability in the assessment of 'adequate' chest excursion during simulated neonatal resuscitation. Neonatology 2011;100(1):99-104.

11. Schmölzer GM, Kamlin OC, Dawson JA, te Pas AB, Morley CJ, Davis PG. Respiratory monitoring of neonatal resuscitation. Arch Dis Child Fetal Neonatal Ed 2010;95(4):F295-F303.

12. Pearlman SA, Zern SC, Blackson T, Ciarlo JA, Mackley AB, Locke RG. Use of neonatal simulation models to assess competency in bag-mask ventilation. J Perinatol 2016;36(3):242-246.

13. Boldingh AM, Solevåg AL, Benth JŠ, Klingenberg C, Nakstad B. Newborn manikin study shows that physicians often fail to detect correct lung compliance when using a self-inflating bag. Acta Paediatr 2016;105(2):172-177.

14. American Academy of Pediatrics, American Heart Association. NRP Neonatal Resuscitation Textbook $7^{\text {th }}$ Edition. Elk Grove Village, Illinois: American Academy of Pediatrics; 2016. 